\title{
Heterogeneity in the Fragmentation of Ziegler Catalyst Particles during Ethylene Polymerization Quantified by X-ray Nanotomography
}

Koen W. Bossers," Roozbeh Valadian," Jan Garrevoet, Stijn van Malderen, Robert Chan, Nic Friederichs, John Severn, Arnold Wilbers, Silvia Zanoni, Maarten K. Jongkind, Bert M. Weckhuysen,* and Florian Meirer*

Cite This: JACS Au 2021, 1, 852-864

Read Online

ACCESS

Llll Metrics \& More

Article Recommendations

Supporting Information

ABSTRACT: Ziegler-type catalysts are the grand old workhorse of the polyolefin industry, yet their hierarchically complex nature complicates polymerization activity-catalyst structure relationships. In this work, the degree of catalyst framework fragmentation of a high-density polyethylene (HDPE) Ziegler-type catalyst was studied using ptychography X-ray-computed nanotomography (PXCT) in the early stages of ethylene polymerization under mild reaction conditions. An ensemble consisting of 434 fully reconstructed ethylene prepolymerized Ziegler catalyst particles prepared at a polymer yield of $3.4 \mathrm{~g} \mathrm{HDPE} / \mathrm{g}$ catalyst was imaged. This enabled a

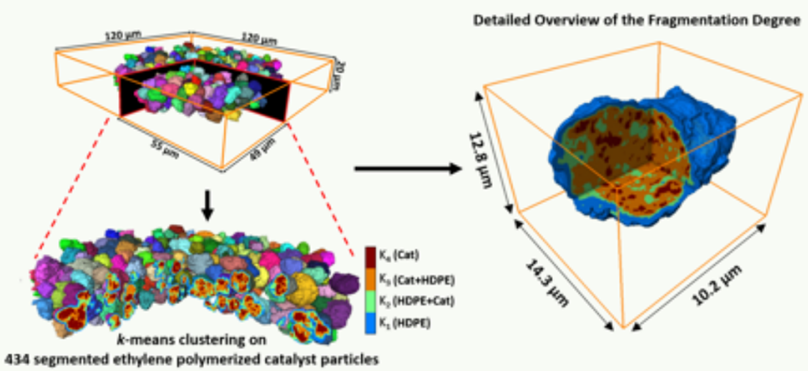
statistical route to study the heterogeneity in the degree of particle fragmentation and therefore local polymerization activity at an achieved 3-D spatial resolution of $74 \mathrm{~nm}$ without requiring invasive imaging tools. To study the degree of catalyst fragmentation within the ensemble, a fragmentation parameter was constructed based on a $k$-means clustering algorithm that relates the quantity of polyethylene formed to the average size of the spatially resolved catalyst fragments. With this classification method, we have identified particles that exhibit weak, moderate, and strong degrees of catalyst fragmentation, showing that there is a strong heterogeneity in the overall catalyst particle fragmentation and thus polymerization activity within the entire ensemble. This hints toward local mass transfer limitations or other deactivation phenomena. The methodology used here can be applied to all polyolefin catalysts, including metallocene and the Phillips catalysts to gain statistically relevant fundamental insights in the fragmentation behavior of an ensemble of catalyst particles.

KEYWORDS: X-ray nanotomography, Ptychography, Catalysis, Ziegler, $\alpha$-Olefin polymerization, Fragmentation, Watershed segmentation, Particle ensemble

\section{INTRODUCTION}

After the discovery of a free radical polymerization route of ethylene into a highly branched low-density polyethylene at extreme reaction conditions in the early 1930s by Gibson and Fawcett, two different catalyst systems, based on, respectively, chromium and titanium active sites, were developed in the 1950s operating at considerably milder reaction conditions and giving a more linear and dense polyethylene product. ${ }^{1-3}$ One of these systems was developed by Karl Ziegler based on combining a $\mathrm{TiCl}_{4}$ precatalyst with a dialkylchloroaluminum cocatalyst to form a $\mathrm{Ti}^{3+}$ active site. This discovery would ultimately result in awarding the 1963 Nobel prize to both Karl Ziegler and Giulio Natta, who discovered that the $\alpha-\mathrm{TiCl}_{3}$ form could also be used for the synthesis of stereoregular polyolefins such as isotactic polypropylene. ${ }^{4,5}$ Today, three different catalyst systems, namely, the Ziegler catalyst, the Phillips catalyst, and molecular, single-center catalyst in homogeneous and immobilized form as well as the non- catalytic process developed by Gibson and Fawcett, are used to synthesize a wide variety of different polyethylene grades ranging from highly branched low-density (LDPE), linear lowdensity (LLDPE), medium-density (MDPE), to high-density (HDPE) polyethylene. ${ }^{6}$ These polyethylene (PE) grades possess different mechanical and physicochemical properties, such as impact strength, stiffness, friction and wear resistance, melting point, and processability, leading to widespread applications ranging from insulating layers for electricity cables, high durability pipes for the transport of gases and liquids, to medical appliances and protective equipment. ${ }^{7}$

Received: March 21, 2021

Published: May 4, 2021 
Finally, polyolefins can also be synthesized from biomass- and municipal waste-derived feedstock, such as ethylene derived from bioethanol and pyrolysis cracking of plastic waste, and they can be implemented in a circular economy through either mechanical or chemical recycling, such as remolding and thermal decomposition to the raw feedstock. ${ }^{8-10}$

The hierarchically complex Ziegler catalyst system remains one of the grand old workhorses of the polyethylene industry (Ziegler-Natta catalyst nomenclature is used when referring to the polypropylene catalyst based on $\mathrm{MgCl}_{2} / \mathrm{TiCl}_{4}$ with added Lewis base donors). It typically consists of a $\mathrm{TiCl}_{4}$ preactive site species epitaxially chemisorbed on a mechanically or chemically activated $\mathrm{MgCl}_{2}$ support matrix and subsequently reduced and alkylated with a trialkylaluminum cocatalyst. ${ }^{2}$ This $\mathrm{MgCl}_{2}$ matrix is a buildup of platelets, as small as $5 \mathrm{~nm}$, referred to as the primary particles. ${ }^{11,12}$ These primary particles stack together due to ionic interactions to form the catalyst particles in the range of $5-30 \mu \mathrm{m} .{ }^{13}$ Depending on the synthesis routes used, the physicochemical and mechanical properties of Ziegler-type catalysts, such as the pore size distribution, can be fine-tuned. ${ }^{14,15}$ For instance, precursors ranging from alkoxides like $\mathrm{Ti}(\mathrm{OR})_{4}, \mathrm{Mg}(\mathrm{OR})_{2}$, and $\mathrm{MgCl}_{2}$ alcohol adducts to $\mathrm{MgRCl}$ Grignard reagents can be used. ${ }^{16-19}$ Furthermore, spray-drying of anhydrous $\mathrm{MgCl}_{2}$ in a polar solvent or the deposition of $\mathrm{MgCl}_{2}$ on a spherical and porous silica support matrix are common industrial preparation routes providing high control of the catalyst particle morphology, particle size distribution, and porosity. ${ }^{20,21}$

The $\alpha$-olefin polymerization process, including the growth of the polyolefin particles, starts with the fragmentation of the catalyst particle at the nanometer to micrometer scale. ${ }^{2-28}$ Typically, this is referred to as the early stage of olefin polymerization. As the $\alpha$-olefin monomer reaches the active site, it will become incorporated in a growing polymer chain. These polymers will be formed both on the external surface and on internal pore structure of the polyolefin catalysts. As these polymer chains start to grow inside the pores of the catalyst particle, there is a buildup of stress exerted on the framework of this respective particle. Depending on the friability of the framework, the crystallization and the growth rate of the formed polymer versus the relaxation time of the induced stress, a threshold is reached at which point the catalyst particle starts to fragment. ${ }^{29-31}$ This fragmentation is a necessary phenomenon as it leads to the exposure of new active sites and prevents mass transfer limitations through the densely formed polyolefin layer that would otherwise inhibit catalyst activity. ${ }^{32,33}$ However, a controlled fragmentation process is preferable to prevent the formation of fines that can lead to fouling in the reactor or downstream equipment as well as to maintain good control over the evolution of particle morphology and particle size distribution (PSD) to facilitate easier polymer powder processing. ${ }^{22,34,35}$ A common approach at industrial plants is to implement a prepolymerization step at mild reactions conditions, e.g., $0.1 \mathrm{MPa}$ and close to room temperature, to facilitate a smooth fragmentation process followed by the actual polymerization conditions of 1-10 MPa and around $364 \mathrm{~K}^{3,36-39}$

From a fundamental aspect, there are two limiting modes of catalyst particle fragmentation, namely, the layer-by-layer or shrinking core mode and the continuous bisection mode. ${ }^{28}$ In the first mode, the polymerization is mainly occurring near the surface of the catalyst particle, and therefore, the catalyst particle starts to fragment from the surface inward until the core is reached. In the second mode, olefin polymerization occurs throughout the entire catalyst particle, which leads to an internal cleavage at the core of the catalyst particle into successively smaller fragments. Which fragmentation mode dominates the overall fragmentation behavior is determined by the type of $\alpha$-olefin monomer and catalyst properties, such as pore size and pore size distribution, crystalline nature of the formed polymer, friability of the framework, distribution, nature and activation procedure of the active sites, as well as heat transfer and mass transfer properties, which are influenced strongly by the operating conditions such as gas phase versus slurry phase. ${ }^{40-44}$

The fragmentation behavior of polyolefin catalyst particles has been studied in the past decades mainly with the use of electron microscopy techniques. ${ }^{45-48}$ Zheng and Loos used cross-sectional scanning electron microscopy (SEM) on both Ziegler-Natta and immobilized metallocene catalysts operating under different reaction conditions. ${ }^{49-51}$ For a propylenepolymerized Ziegler-Natta catalyst, they observed that as a function of the pore size, either the shrinking core or continuous bisection mode was dominating. ${ }^{50}$ These findings signify the crucial role that catalyst pore size and mass transfer resistance play in the fragmentation behavior. Interestingly, an immobilized metallocene catalyst showed a dominating shrinking core fragmentation behavior under ethylene polymerization conditions and continuous bisection fragmentation behavior under propylene polymerization conditions. ${ }^{49}$ The McKenna group showed in a series of articles the development of stopped-flow reactors and a rapid quenchedflow device that allowed the investigation of the early stages of ethylene polymerization under industrially relevant conditions both in the gas-phase and slurry-phase conditions. ${ }^{52-56}$ These unique polymerization reactors achieved reaction times as low as $40 \mathrm{~ms}$ at industrially relevant reaction conditions, such as 0.8 $\mathrm{MPa}$ ethylene. Pater et al., on the contrary, developed a reactor setup that allowed the prepolymerization of a Ziegler-Natta catalyst with propylene under extremely low reaction rates to obtain well-defined polymerization conditions, which allowed studying the intra- and interparticle morphologies with crosssectional SEM. ${ }^{38}$ Unfortunately, these electron-microscopybased studies require either invasive and destructive cutting techniques to observe a 2-D representation of the interior of the particle or are limited to information regarding exclusively the particle's exterior.

Fortunately, state-of-the-art X-ray microscopes both at synchrotron-based and lab-based facilities are able to image the interior and exterior of objects, such as catalyst and polymer particles ranging from several tens of microns to even millimeters in size with 3-D achieved spatial resolution ranging from sub-100 $\mathrm{nm}$ to several microns without requiring invasive preparation methods. ${ }^{56}$ Additionally, the high beam brilliance and tunability of the photon energy at synchrotrons has enabled chemical, elemental, and diffractive tomographic imaging, even under operando catalytical conditions. ${ }^{57-64}$ For example, the Beale group recently demonstrated the advances made in operando X-ray tomographic imaging for both the oxidative coupling and re-forming of methane. ${ }^{65,66}$ Due to the state-of-the-art photon detector and advanced online data analysis, the collection of each X-ray diffraction computed tomography (XRD-CT) data set only took $117 \mathrm{~s}$ with a pixel size close to $3 \mu \mathrm{m} .{ }^{65}$ They further demonstrated the use of a multimodal $\mu$-X-ray fluorescence/absorption/XRD CT toolbox. ${ }^{66}$ Another exciting development, performed by 


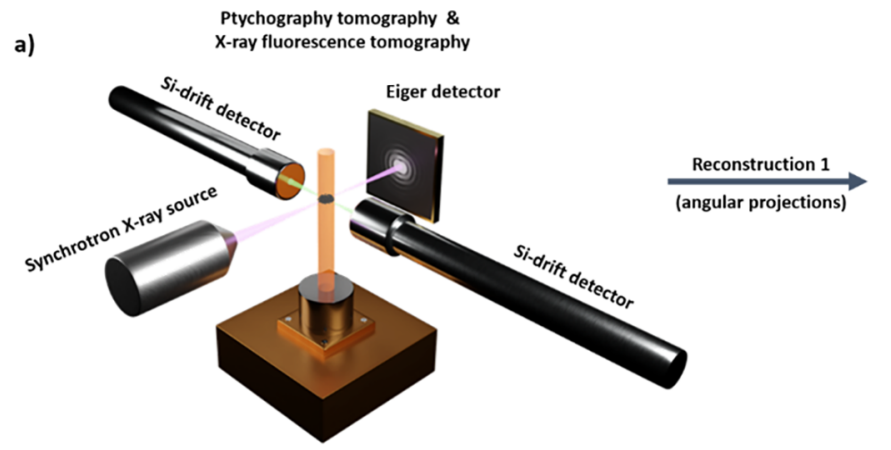

b)

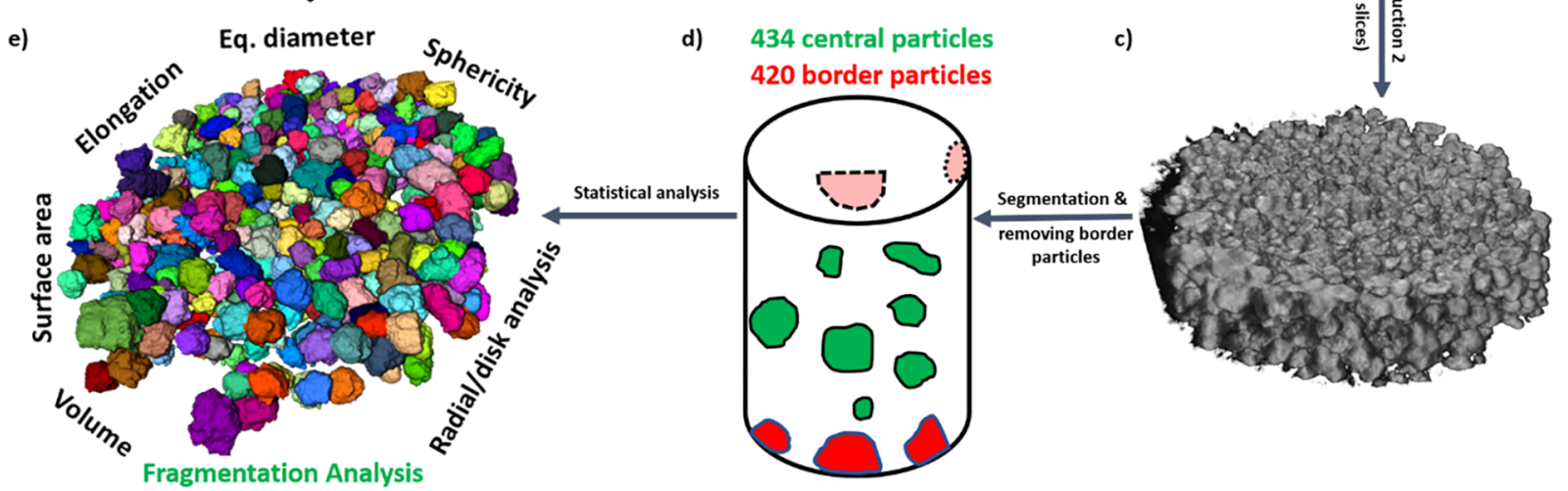

f)

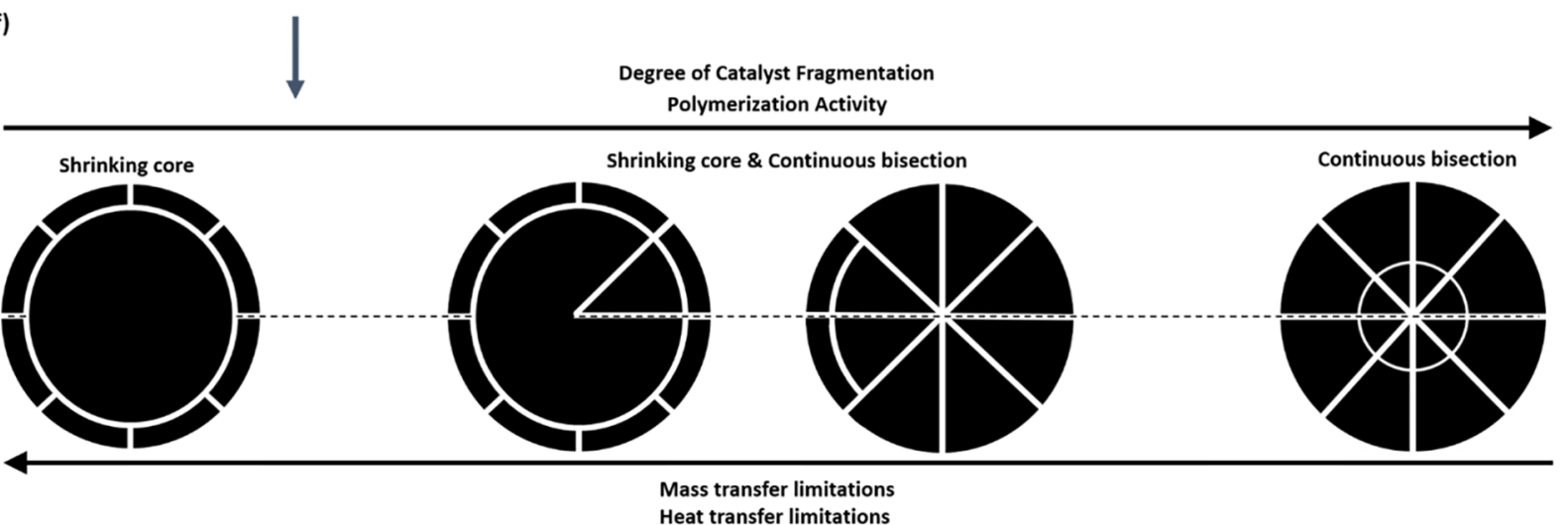

Figure 1. X-ray ptychography and fluorescence nanotomography on an ensemble of ethylene prepolymerized Ziegler-type catalysts. (a) Schematic representation of the correlated X-ray ptychography and fluorescence tomography setup used at the P06 beamline at DESY. The beam was focused onto the sample by KB mirror optics, and the X-ray fluorescence signal was detected using 2 side-looking silicon drift detectors. An Eiger X 4M detector behind the sample was used to record the diffraction data for PXCT. (b) Reconstructed 2-D X-ray ptychography projections at different angles. (c) 3-D reconstructed volume of the real part of the refractive index represented as grayscale intensity. (d) After a watershed segmentation procedure, composite polymer-catalyst particles that were cutoff from the field of view were classified as "border particles" and not included in the subsequent statistical analysis. (e) Remaining 434 segmented particles were then analyzed with respect to their geometrical properties and fragmentation behavior. (f) Schematic representation of the relationship between the dominating or highly mixed limiting modes of fragmentation behavior observed, namely, the shrinking core and continuous bisection, versus the catalyst particle's polymerization activity and degree of catalyst fragmentation, which hints toward strong local mass and heat transfer limitations.

the Grunwaldt group, has shown the strengths of correlative multimodal spectroscopy and 3-D imaging techniques bridging the fields of electron, ion, and X-ray tomography. ${ }^{67-69}$ Furthermore, they recently reported on the fabrication of two nanoreactors for in situ electron and X-ray tomographic studies, allowing pressures and temperatures of up to $100 \mathrm{kPa}$ and $1573 \mathrm{~K}$ with a tilting angle of $\pm 35^{\circ}$ for a fully mounted cell. ${ }^{70}$ The van Bokhoven group recently reported on a 3-D estimated spatial resolution between 30 and $40 \mathrm{~nm}$ for the subvolume of several fluid catalytic cracking (FCC) catalyst particles using ptychographic X-ray-computed tomography (PXCT). ${ }^{71-74}$ They found that zeolite amorphization and structural changes are the underlying driving forces for the
FCC catalyst deactivation process. ${ }^{73} \mathrm{X}$-ray nanotomography studies on FCC catalysts, performed by Bare et al., ${ }^{75}$ as well as by our group, ${ }^{76-83}$ demonstrated how the generation of a 3-D pore network for FCC catalyst particles allowed for advanced mass transport simulation studies as well as correlated localization of active sites, metal poison species, and coke species. Pioneering work on the use of computed X-ray microscopy tomography for the field of polyolefin catalysis was performed in the early 1990s at Brookhaven National Laboratory and subsequently in the late 2000 s, ${ }^{28,84-88}$ with achieved spatial resolution of several microns, allowing the study of porosity of full polyolefin particles and to calculate monomer diffusion and degassing properties. ${ }^{33}$ A recent review 
a)
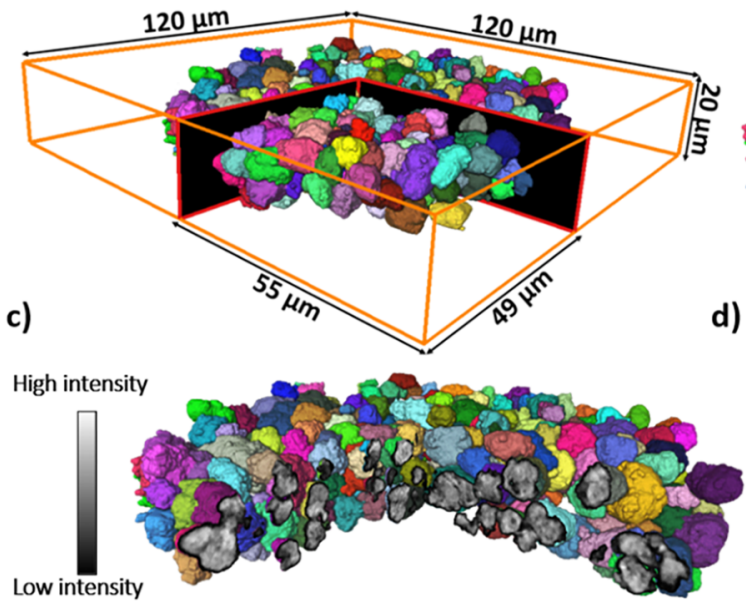

b)

d)
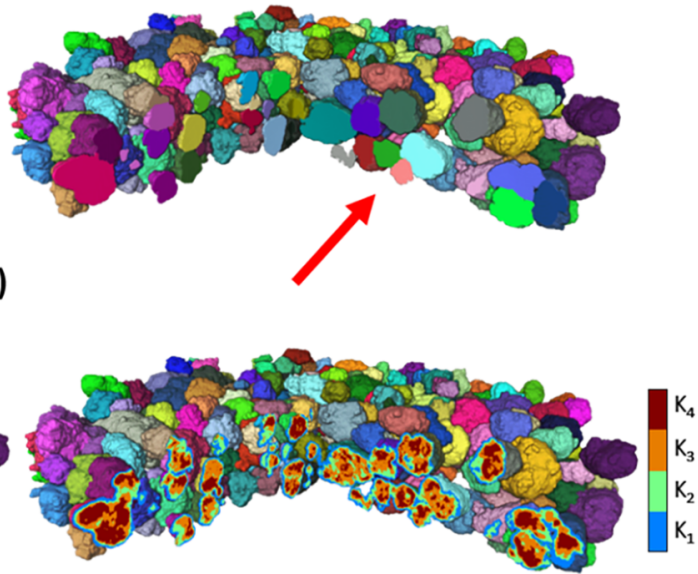

Figure 2. (a) 3-D volume rendering $\left(45.4 \times 45.4 \times 45.4 \mathrm{~nm}^{3}\right.$ voxel size $)$ of the tomography data after manual marker-based watershed segmentation resulting in 434 individually labeled particles. The black planes with red outline depict the position for the visualization of the cross sections in $\mathrm{b}-\mathrm{d}$. (b-d) Cut-out volumes showing, respectively, (b) complete particle labels, (c) overlay of the PXCT grayscale intensity values within these labels, and (d) $k$-means clustering results using four clusters $\left(\mathrm{K}_{1}-\mathrm{K}_{4}\right)$ to segment the PXCT grayscale intensity values.

summarizes the field of X-ray imaging of solid catalysts, including some future perspectives. ${ }^{64}$

In our recent work, we have introduced a powerful correlated 3-D X-ray ptychography and fluorescence microscopy toolbox that allowed us to directly observe in 3-D the Ti distribution, comprising the active sites, within the isotactic polypropylene phase of an individual Ziegler-Natta catalyst particle in the early stages of propylene polymerization. ${ }^{89}$ This study showcased that for the slurry-phase propylene-polymerized catalyst particle, both fragmentation models were present within the same particle, but furthermore that the continuous bisection model was dominating the overall fragmentation behavior. In the current work, we build further upon the use of this powerful correlated 3-D X-ray microscopy toolbox, with a strong focus on the PXCT data set that allowed us to study the heterogeneity in catalyst fragmentation and obtain geometrical parameters of many individual ethylenepolymerized Ziegler-type catalyst particles from an ensemble of 434 particles within the measured field of view.

\section{RESULTS AND DISCUSSION}

In Figure 1, a schematic overview of the experimental approach is given, starting from the setup of the synchrotron-based correlated X-ray ptychography and fluorescence (XRF) tomography setup to the 3-D reconstruction of the ptychographic data set and marker-based watershed segmentation resulting in 434 individual Ziegler-type ethylene polymerization catalyst particles used for the statistical analysis of the fragmentation behavior. As in our previous work, ${ }^{89}$ the Ziegler catalyst was sealed inside a Kapton capillary to prevent hydration of the highly sensitive $\mathrm{MgCl}_{2}$ framework, which would otherwise result in morphological changes and prohibit a study on the fragmentation behavior.

By optimizing the drying procedure after the slurry-phase reaction, minimal beam-induced morphological changes were observed during the collection of $3602-\mathrm{D}$ projections with a total acquisition time of $22 \mathrm{~h}$ (see Figure S4). This resulted in an estimated Fourier shell correlation 3-D spatial resolution of $74 \mathrm{~nm}$ for the PXCT data set (see Figure S8) for a large field of view of $120 \times 120 \times 20 \mu \mathrm{m}^{3}$. The XRF data set was used to support the segmentation of the PXCT data (confirming the presence of $\mathrm{Ti}$ in all particles); however, the low signal-to-noise ratio of the XRF data did not allow for a detailed analysis of the $\mathrm{Ti}$ distribution within individual particles (see Supporting Information, section 7) as done in our previous work. In this work, a new strategy has been devised based on the achieved high spatial resolution of the PXCT data and using a $k$-means clustering method to study and quantify the degree of fragmentation of each individual particle within the entire ensemble using a classification based on a designed fragmentation parameter. A relationship between the degree of catalyst fragmentation and therefore local polymerization activity and the observed fragmentation behavior within an ethylene-polymerized catalyst particle was found and is represented schematically in Figure 1f.

The Ziegler-type catalyst used for this work is an industrially relevant $\mathrm{MgCl}_{2} / \mathrm{TiCl}_{4}$-based system that was chosen specifically for its small $D_{50}$ value of $3.64 \mu \mathrm{m}$ and narrow particle size distribution (span of 1.04; see Supporting Information, section 1). Ethylene polymerization was carried out under mild conditions at 2.6 bar ethylene and room temperature with triethylaluminum as cocatalyst in the slurry phase at short polymerization times to give a yield of $3.4 \mathrm{~g}$ of $\mathrm{HPDE} / \mathrm{g}$ catalyst. This gives a theoretical $D_{50}$ of $5.9 \mu \mathrm{m}$ for the HDPEcatalyst composite particles based on eq $\mathrm{S} 1$.

In Figure S6, a flowchart is given, starting with the acquisition of the raw data from both X-ray ptychography (far-field diffraction patterns) and fluorescence tomography to the ptychographic reconstruction of the real part of the refractive index of the sample components, which is related to the local electron density and therefore local mass density according to eqs S4 and S5. After alignment of the 2-D projections with respect to the center of rotation and to correct for sample drift and motor inaccuracies, the 3-D PXCT volume was reconstructed using filtered back projection with a $45.4 \times$ $45.4 \times 45.4 \mathrm{~nm}^{3}$ voxel size followed by removing noise in $3-\mathrm{D}$ using a nonlocal means filter algorithm. The XRF data set was reconstructed with an iterative algorithm (iART) with a $200 \times$ $200 \times 200 \mathrm{~nm}^{3}$ voxel size. An in-depth methodology description of the reconstruction of both PXCT and XRF 
Table 1. Overview of the Mean and Standard Deviation Values of the Volume (V), Surface Area (SA), and Equivalent Spherical Diameter (ESD), the 10, 50, 90 Percentile Fraction of Particle Size $\left(D_{x}\right)$ and Their Span, Sphericity, Elongation, and Flatness Values for the 434 Completely Reconstructed Ethylene Polymerized Catalyst Particles

\begin{tabular}{cccccccccc}
$V\left(\mu \mathrm{m}^{3}\right)$ & $\mathrm{SA}\left(\mu \mathrm{m}^{2}\right)$ & $\mathrm{ESD}(\mu \mathrm{m})$ & $D_{10}(\mu \mathrm{m})$ & $D_{50}(\mu \mathrm{m})$ & $D_{90}(\mu \mathrm{m})$ & span & sphericity & elongation & flatness \\
$109.5 \pm 79.2$ & $144.2 \pm 67.0$ & $5.69 \pm 1.17$ & 4.40 & 5.61 & 6.87 & 0.44 & $0.74 \pm 0.04$ & $0.60 \pm 0.16$ & $0.67 \pm 0.13$ \\
\hline
\end{tabular}

a)

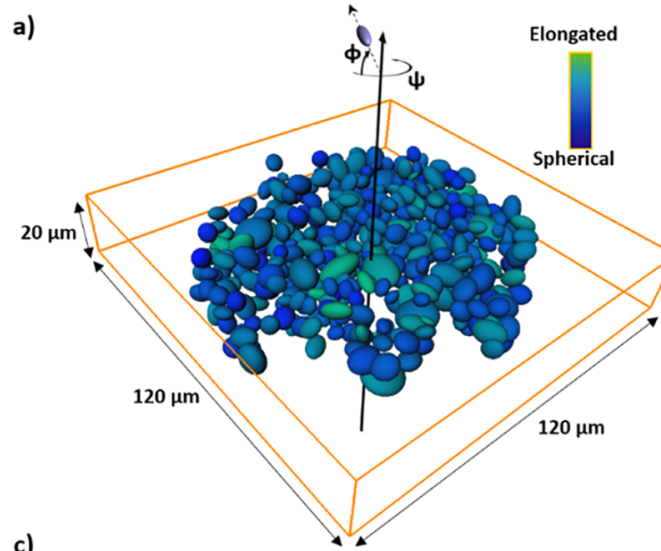

c)

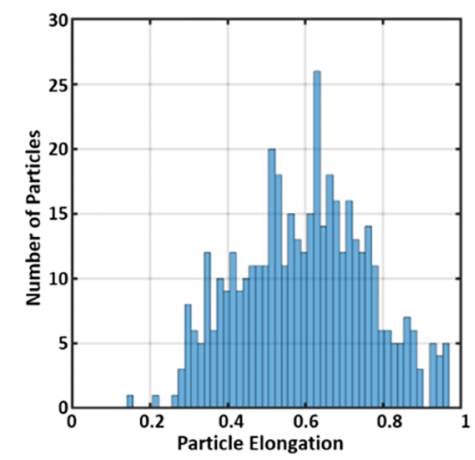

b)

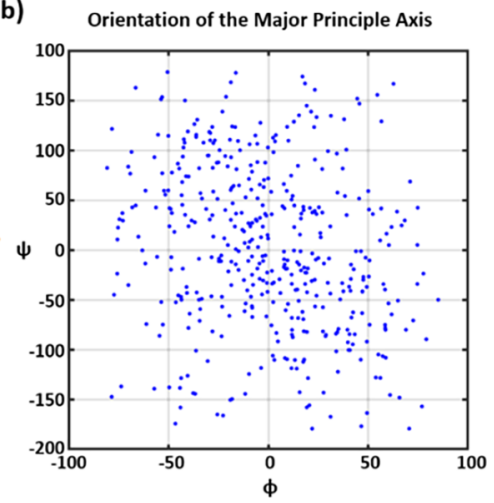

d)

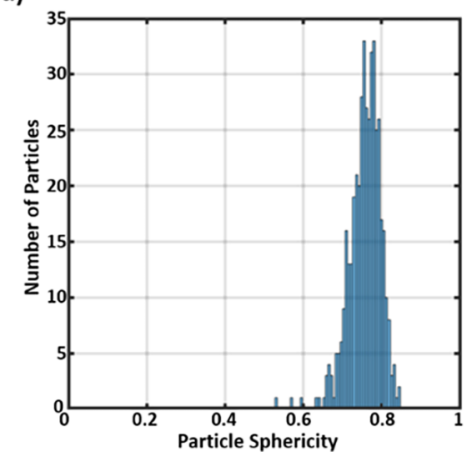

Figure 3. (a) 3-D volume rendering of the orientation and degree of elongation of the 434 ethylene-polymerized catalyst particles. A dark blue color represents a high degree of sphericity, whereas a light green color represents a high degree of elongation. (b) Plot between the $\psi$ (yaw) and $\varphi$ (pitch) Euler angles that shows the orientation of the major principle axis, the elongation direction, of a particle. (c) Histogram of the elongation values of all particles, where a value of 0 means highly elongated and a value of 1 means highly spherical. (d) Histogram of the sphericity values of all particles, where a value of 1 means a perfect sphere.

data sets is given in the Supporting Information, section 5. At this point, the reconstructed PXCT volume, as shown in Figure 1c, contains many highly connected composite particles. Therefore, due to this high particle connectivity, a standard labeling procedure on the polymerized catalyst particle ensemble of either the ptychographic or XRF reconstructed volumes would result in a single label being assigned to all particles. In Figures S1 and S3, SEM images of the pristine and prepolymerized catalyst particles are shown. Indeed, one can observe here that the prepolymerized catalyst particles are highly aggregated and polymer fibers are acting as an interparticle glue. Various explanations can be found, such as (i) a high catalyst concentration in the lab-based model reactor ( $5 \mathrm{~g}$ of catalyst/L diluent), meaning that the odds of two or more catalyst particles to be in close vicinity is increased, or (ii) a relatively high ethylene polymerization versus crystallization rate at the catalyst surface and (iii) absence of a chain terminating agent, such as $\mathrm{H}_{2}$, causing the formation of long polymer fibers that can lead to interparticle entanglements and hence agglomeration. It should be noted that this is not the same as reactor fouling, as it was observed that with increased polymerization time and therefore an increase of the size of each composite polymer-catalyst particle at a certain point, the hydrodynamic forces from the stirring are able to cause a deagglomeration, and finally individual and spherical polymer particles are obtained.

To overcome this problem of highly connected particles, a marker-based watershed algorithm using manually generated markers was employed for the segmentation into separated particles. ${ }^{90,91}$ The strategy to manually draw the markers in 3D provided a supervised control over the segmentation process (see Supporting Information, section 8). Finally, 434 completely reconstructed particles were identified and used for subsequent analysis. The result of the manual marker-based watershed segmentation in separating and classifying the particles is shown in Figure 2. In Figure 2b, indicated by the red arrow, the advantage of using manual markers can be seen in the successful segmentation of the cyan, light green, light pink, and red colored particles. In Figure $2 c$,d, respectively, the overlay of the grayscale and $k$-means segmented electron density on the particle labels is visualized.

With the successful segmentation of the highly agglomerated particle ensemble into 434 individual particles, geometrical parameters, such as the particle's volume, area, equivalent spherical diameter (ESD), PSD, sphericity, elongation, and flatness could be analyzed. The calculation of these particle 
metrics is described in Supporting Information, section 9. The mean and standard deviation values of these particle metrics are provided in Table 1 . The geometrical parameters concerning the particle shape such as sphericity, elongation, and flatness show a quite narrow distribution, especially for the sphericity with a standard deviation of $4 \%$. This shows that the overall particle morphology within the entire ensemble is relatively homogeneous. In the case of a smooth catalyst fragmentation process, the morphology of the catalyst particle has been observed experimentally to be replicated in the final polymer particle, called the replication phenomenon. ${ }^{47,92}$ The mean elongation of 0.60 (value $=1$ for a perfect sphere) for the composite polymer-catalyst particles confirms the presence of the morphological replication phenomena as the pristine catalyst based on SEM observations given in Figure S1 and is also slightly elongated. In Figure $3 \mathrm{a}$, both the degree and orientation of the elongation of each particle are visualized in $3-D$. Additionally, in Figure $3 b$, the correlation is plotted between the $\psi$ (yaw) and $\varphi$ (pitch) Euler angles of the major principal axis of each particle, which represent the direction of the elongation (see Supporting Information, section 9 for a detailed explanation). Finally, the histograms showing the elongation and sphericity values within the entire ensemble are given in, respectively, Figure $3 \mathrm{c}$,d. Based on this plot, no clear preferred orientation is observed for the elongation axis within the ensemble. Therefore, although the composite particles themselves are elongated and highly agglomerated, the nonordered orientation of the elongation direction of the particles of the ensemble shows that there is no preferred expansion direction of the agglomeration as a whole (spheroidal). Furthermore, having measured a relatively large ensemble of particles allows us to calculate the PSD, which can then be compared to both the theoretically expected $D_{50}$ based on the polymer yield or bulk particle size measurement techniques such as static laser scattering (SLS). In Table 1, the ESD and PSD ( $D_{10,50,90}$ and span) of the composite particles are given. The calculated $D_{50}$ of $5.61 \mu \mathrm{m}$ of the center particles is only $5.8 \%$ smaller than that of the calculated $D_{50}$ of $5.96 \mu \mathrm{m}$ based on eq S1 (at a yield of $3.4 \mathrm{~g}$ of HDPE/g catalyst).

However, with respect to the span calculated for the pristine catalyst of 1.04 based on SLS results, the span and thus a measure of the width of the particle size distribution found here with PXCT of 0.44 is considerably smaller. This can be explained by the intrinsic differences between the two techniques, such as better bulk statistics with SLS, the method used to interpret the ESD values from the SLS raw data, and that SLS measures the ESD of the scattering objects in the path length of the laser source, meaning that agglomerated objects are considered as a single particle in SLS and can thus increase and broaden the PSD determined. This last argument was indeed observed experimentally here for the agglomerated composite polymer-catalyst particles, where the SLS results gave $D_{50}$ values going from $350 \mu \mathrm{m}$ down to $160 \mu \mathrm{m}$ during the collection of multiple measurements where increased stirring time was observed to cause partial deagglomeration.

The $\mathrm{MgCl}_{2}$ framework consisting of $\mathrm{MgCl}_{2}$ platelets as small as $5 \mathrm{~nm}$ bound through ionic interactions has a higher friability compared to that of the covalently bound $\mathrm{SiO}_{2}$ framework used for other polyolefin catalyst types, such as the metallocene and Philips catalysts (although $\mathrm{SiO}_{2} / \mathrm{MgCl}_{2} / \mathrm{TiCl}_{4}$ Ziegler-type catalysts are also in use). ${ }^{11,13,28-31,92,93}$ This typically facilitates a faster degree of framework disintegration for $\mathrm{MgCl}_{2}$-based catalysts. Filling of the pore network of the Ziegler catalyst (main pore size distribution $=20-50 \mathrm{~nm}$ of the catalyst studied here) due to the local polymerization of ethylene and subsequent fragmentation caused by the stress on the framework is therefore expected to lead to a high mixing of the polymer and catalyst phases below the achieved PXCT 3-D spatial resolution of $74 \mathrm{~nm}$. X-ray ptychography probes the real part of the refractive index, $\delta$, which is directly related to the local electron density, $\rho_{\mathrm{e}}$, contained within the volume of each voxel, as shown in eq S4. Additionally, eq S5 shows that the local $\rho_{\mathrm{e}}$ is dependent on the concentration of each chemical phase present within that probed volume that has a different mass density, $\rho_{\mathrm{m}}$. This intimate mixing of the polymer and catalyst phases leads to a strong broadening of the histogram of the electron density intensity values (see Figure S12). However, since the polymer and catalyst phases have different $\rho_{\mathrm{m}}$ values of, respectively, $\sim 0.95 \mathrm{~g} / \mathrm{cm}^{3}$ for HDPE and $\sim 2.32$ $\mathrm{g} / \mathrm{cm}^{3}$ for the catalyst (assuming bulk anhydrous $\mathrm{MgCl}_{2}$ ), their mixing will provide a range of weighted electron density values that portray their relative concentrations, as shown in eq S5. This means that a subvolume dominant in a catalyst phase will have an average electron density higher than that of an equally mixed subvolume of HDPE and catalyst, which in turn will be higher than that of a subvolume dominant in HDPE. A $k$ means clustering algorithm was used to separate the PXCT grayscale intensity values in four mixed chemical phases (see Supporting Information, section 10). The conventional Otsu's method is expected to give the same result for this multilevel thresholding but is computationally more exhaustive as it searches for a global optimal threshold with respect to the local optimal threshold search by the $k$-means algorithm. ${ }^{94}$ These four $k$-means clusters are sorted here in terms of increasing average electron density as follows: $\left(\mathrm{K}_{1}\right)$ a HDPE-dominant phase, $\left(\mathrm{K}_{2}\right.$ and $\left.\mathrm{K}_{3}\right)$ two highly mixed HDPE catalyst phases where in $\mathrm{K}_{2}$ and $\mathrm{K}_{3}$, respectively, the HDPE or catalyst has a higher concentration in that voxel's volume, and finally $\left(\mathrm{K}_{4}\right)$ a catalyst-dominant phase. The $k$-means partitioned grayscale intensity histogram along with the mean grayscale intensity of each $k$-means cluster is given in Figure S11.

Therefore, in this work, to study the degree of catalyst fragmentation within each composite particle, a unitless fragmentation parameter, referred to as $V_{r}$, has been designed and calculated that considers both the spatially resolved catalyst fragments (identified via $\mathrm{K}_{4}$ ) and the quantity of the formed HPDE phase (via clusters $\mathrm{K}_{1-3}$ ) directly using the $k$ means clusters. A brief description of this parameter is given below; a more detailed explanation can be found in the Supporting Information, section 11.

$V_{\mathrm{r}}$ provides a relationship between the formed HDPE phase and the fragmented catalyst phase. This is achieved by taking the ratio of the total volume of the first three $k$-means clusters of each particle, $K_{1,2,3}$, which constitutes both the polymer and the spatially nonresolved catalyst fragments, over the mean volume of the spatially resolved catalyst fragments in the fourth $k$-means cluster, $\mathrm{K}_{4}$. These spatially resolved catalyst fragments in the $\mathrm{K}_{4}$ cluster are referred to as the nonconnected components.

In the Supporting Information, section 12, two different fragmentation parameters that only take the catalyst fragmentation into account (that is to say it does not include polymer formation) are compared to the parameter $V_{\mathrm{r}}$. Whereas these other parameters fundamentally speaking should be sufficient to study the catalyst fragmentation degree, the spatial resolution limits their usefulness since catalyst 
fragments smaller than $74 \mathrm{~nm}$ are most likely to either disappear to the $K_{1,2,3}$ clusters or appear as part of a larger fragment in $\mathrm{K}_{4}$.

In Table 2, the mean, median, minimum, and maximum values as well as the standard deviation of the parameter $V_{\mathrm{r}}$ for

Table 2. Overview of the Mean, Median, Minimum, and Maximum Values and the Standard Deviation of the $V_{\mathrm{r}}$ Fragmentation Parameter as Calculated for the 434 Composite Particles in the Imaged Ensemble to Study the Degree of Catalyst Fragmentation

\begin{tabular}{cccccc}
$\begin{array}{c}\text { fragmentation } \\
\text { parameter }\end{array}$ & $\begin{array}{c}\text { mean } \\
\text { value }\end{array}$ & $\begin{array}{c}\text { median } \\
\text { value }\end{array}$ & $\begin{array}{c}\text { minimum } \\
\text { value }\end{array}$ & $\begin{array}{c}\text { maximum } \\
\text { value }\end{array}$ & $\begin{array}{c}\text { standard } \\
\text { deviation }\end{array}$ \\
$V_{\mathrm{r}}$ & 436 & 268 & 13 & 7180 & 549 \\
\hline
\end{tabular}

the 434 imaged composite particles in the ensemble are reported. While the unitless values themselves have no physical meaning, the large spread of $V_{\mathrm{r}}$, as evidenced by the standard deviation being larger than the mean, nonetheless shows that there is significant heterogeneity in the degree of catalyst fragmentation within the ensemble. To visualize this heterogeneity, the central slice along the $X Y$ plane of each of the 434 composite particles is displayed in Figure 4. Here, we

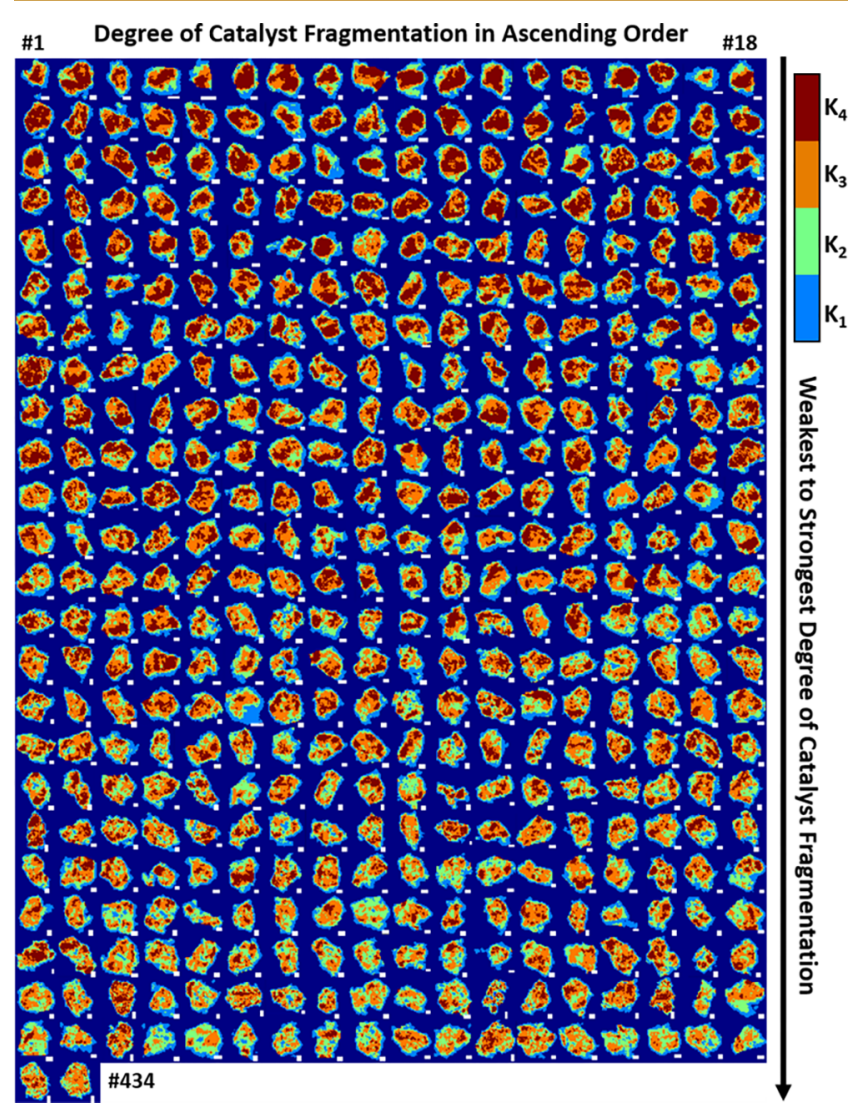

Figure 4. "Family album" of virtual cross sections through all evaluated catalyst particles. The figure shows the results of the $k$ means cluster analysis of the PXCT grayscale values of the central slice of each particle. Particles have been sorted by their degree of catalyst fragmentation from weakest, at the top left, to strongest, at the bottom left, fragmentation degree within the entire ensemble of 434 particles based on the unitless $V_{\mathrm{r}}$ fragmentation parameter. The white scale bar at the bottom right of each central image depicts a size of 1 $\mu \mathrm{m}$. chose to visualize the distribution of the $k$-means clusters as it provides a clear overview of the HPDE-rich, highly mixed, and catalyst-rich phases. It should be noted that only one central slice is visualized here for simplicity and therefore does not provide the 3-D overview of each particle in terms of the degree of fragmentation and fragmentation behavior (type of fragmentation model dominating). The particle at the top left has the lowest $V_{\mathrm{r}}$ value and exhibits the weakest degree of catalyst fragmentation. It therefore exhibited the lowest local ethylene polymerization activity, whereas the particle on the bottom left showed the largest $V_{\mathrm{r}}$ value and thus the strongest degree of catalyst fragmentation and in turn the highest local polymerization activity. The heterogeneity in the degree of fragmentation of each particle and therefore the local polymerization activity observed are most likely the result of mass transfer limitations induced by the particle agglomeration. The particle agglomeration in turn could be caused by the high concentration of the catalyst used in the model reactor ( $5 \mathrm{~g}$ of catalyst/L diluent) that leads to a higher probability of catalyst particles undergoing ethylene polymerization to stick together. These agglomerations would then limit the diffusion of ethylene to all the otherwise available $\mathrm{Ti}$ active sites within each individual particle. Other deactivation phenomena such as the presence of poisons and heat transfer limitations seem less likely due to the presence of excess triethylaluminum cocatalyst, which also acts as a scavenger for poisons and the slurry-phase operation under mild reaction conditions ( 2 bar ethylene, room temperature) to facilitate better heat transfer.

After all particles had been sorted according to their respective degree of fragmentation within the entire ensemble using the $V_{\mathrm{r}}$ fragmentation parameter, it became possible to look more in-depth into the fragmentation behavior of particles that exhibited either a weak, moderate, or strong degree of catalyst fragmentation. In Figure 5, three particles have been selected that fall in one of these three groups. The volume renderings report the 3-D distribution of the four $k$-means clusters and show how each particle is enveloped in a shell of the HDPE-dominant $K_{1}$ (blue) cluster. However, from the surface toward the core of each particle, we observe a mix of $\mathrm{K}_{2}$ (in green), $\mathrm{K}_{3}$ (orange), and even $\mathrm{K}_{4}$ (red), depending on the particle's fragmentation degree. In Movies S2-S4 the 3-D volume rendering of these three particles is given for a full overview of the distribution of the clusters. To complement this visualization, the radial distribution of the volume ratio of each cluster is reported in Figure 5b (see Supporting Information, section 12 for a detailed explanation). This radial analysis gives the volume ratio of each $k$-means cluster at a single voxel shell, which is normalized by the total voxel count in that shell, at a certain distance from the surface. At the core of a particle and hence the largest distances from the surface, the volume ratio can therefore show an abrupt behavior since that shell consists only of a few (central) voxels. For the first particle, we observe that, at the surface, the HDPE-dominant $\mathrm{K}_{1}$ cluster has the largest volume ratio, and as we go toward the core, the highly mixed HDPE-catalyst $\mathrm{K}_{2}$ and $\mathrm{K}_{3}$ clusters sequentially dominate the volume ratio in a shell followed finally by the catalyst-dominant $\mathrm{K}_{4}$ cluster and again a rise in the volume ratio of $\mathrm{K}_{3}$ close to the center. In fact, this type of alternating sequence strongly fits to the shrinking-core fragmentation model, where the main catalyst polymerization activity is occurring at the particle's external surface and leads to the peeling of typically small catalyst fragments of the 


\section{Degree of Fragmentation}

a)

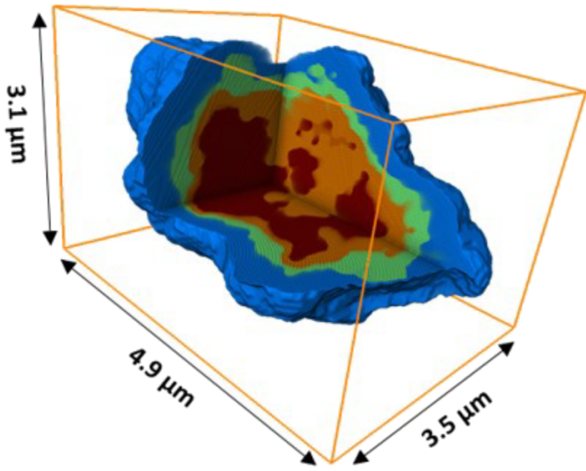

b)

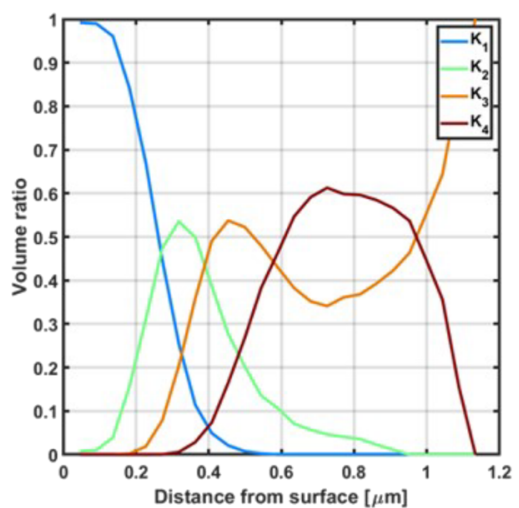

c)

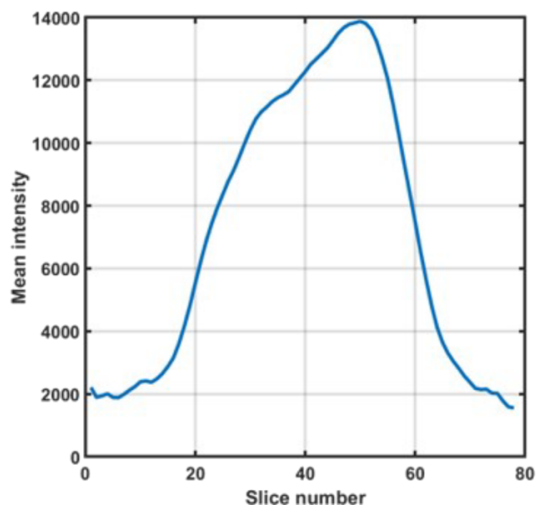

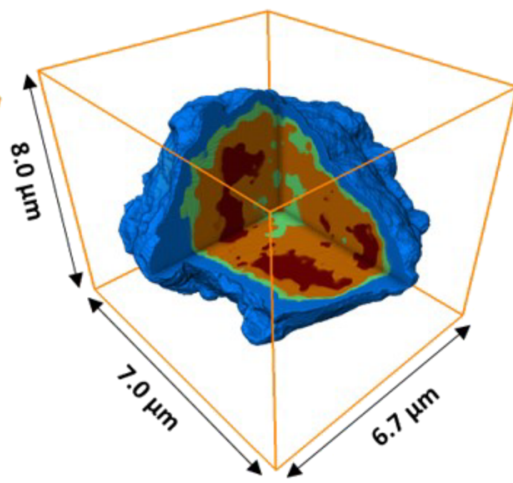
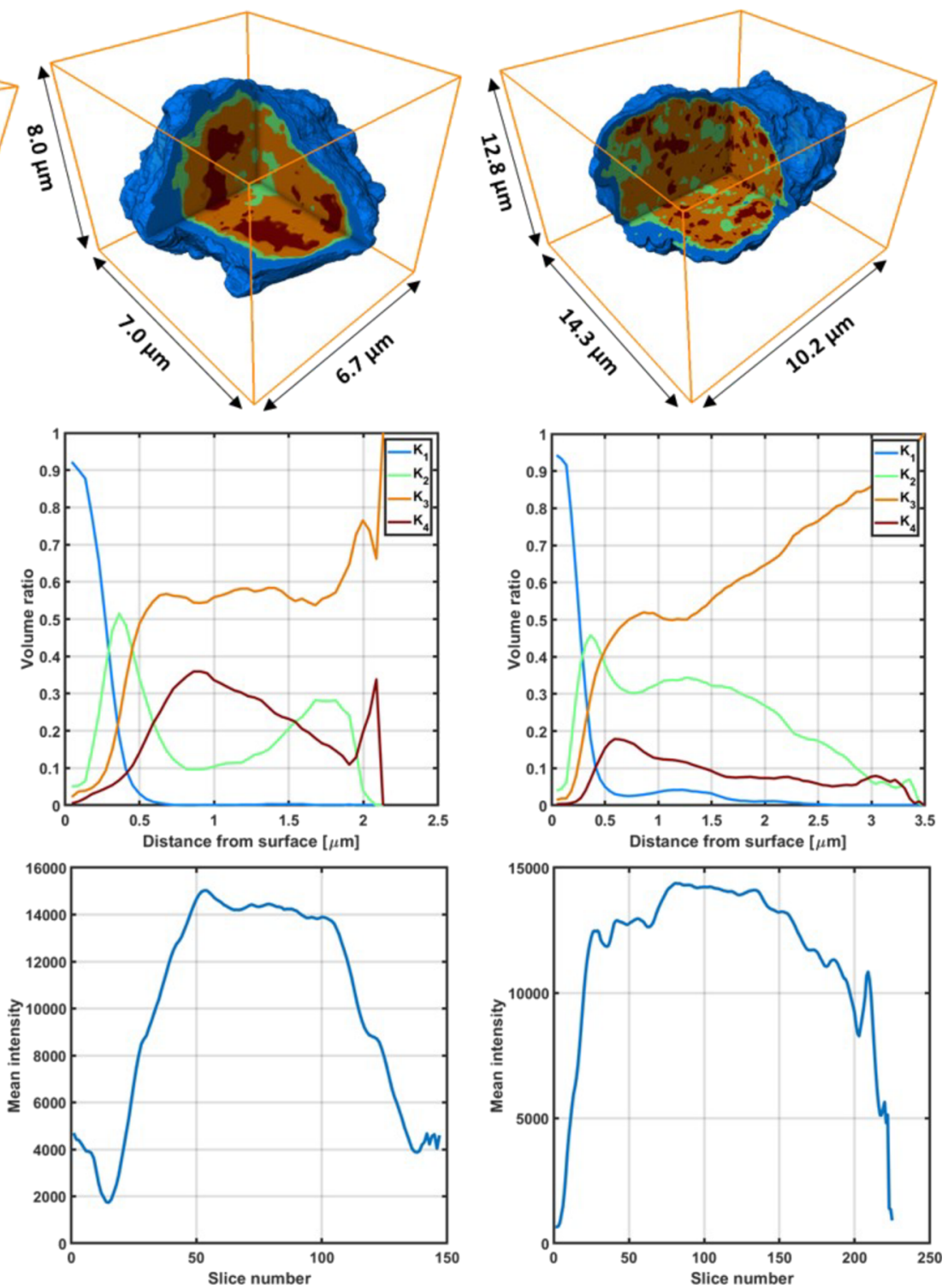

Figure 5. (a) Cross-sectional volume rendering of the $k$-means clustering of the grayscale intensities from three composite particles representing from left to right, respectively, the weakest, moderate, and strongest degrees of catalyst fragmentation as based on their sorting by the parameter, $V_{\mathrm{r}}$. (b) Radial analysis of the volume ratio of each $k$-means cluster going from the surface of the respective particle toward the core. (c) Disk analysis along the $X Y$ plane giving the mean grayscale intensity value of each slice going from one edge of the particle to the other.

original catalysts external surface that will become partitioned to the $\mathrm{K}_{1,2,3}$ clusters depending on the volume ratio of HDPE to catalyst in a voxel. Additionally, the increase of $\mathrm{K}_{3}$ at the core could point toward the formation of polyethylene also inside the core of this particle, which the visual cross section in Figure 5a confirms. The formation of polyethylene at the core could indicate that also the continuous bisection model is occurring for this weakly fragmented particle, albeit with a seemingly lower contribution to the overall fragmentation behavior than the shrinking core.

The external surfaces of the other two more fragmented particles are still composed of first the $\mathrm{K}_{1}$ cluster followed by an increase of the $K_{2}$ cluster, which shows that the shrinking core model is still occurring for these more active particles. However, whereas the first particle shows a clear sequential profile between all four clusters going from the surface to the core, a change in this behavior is observed for the other two particles. For instance, the moderately fragmented particle has a second local maximum of the $\mathrm{K}_{2}$ cluster close to the center of the particle. Furthermore, the $\mathrm{K}_{3,4}$ clusters are more homogeneously distributed throughout this particle, with a constant higher concentration of $\mathrm{K}_{3}$ over $\mathrm{K}_{4}$ at each distance from the surface. This means that for this moderately fragmented particle, considerable amounts of polyethylene have now also been formed at the core of the particle in addition to the polymer layer at the surface $\left(\mathrm{K}_{1,2}\right)$, which has stayed almost constant in terms of volume ratio width (number of voxel shells). Here, the formation of polyethylene at the core of the particle has led to sufficient local fragmentation to push spatially resolved catalyst fragments $\left(\mathrm{K}_{4}\right)$ toward the surface of the particle. The dispersion of large $\mathrm{K}_{4}$ fragments toward the surface of the particle and presence of the $K_{2,3}$ clusters at the 
core of the particle is also observed in the visualization of the cross section of this moderately fragmented particle in Figure 5a. This shows that now, in addition to the shrinking core fragmentation model, the continuous bisection fragmentation model is also playing a significant role in the overall fragmentation behavior of this moderately fragmented particle. Finally, for the strongest fragmented particle, the most homogeneous distribution of $\mathrm{K}_{2,3,4}$ is observed as we go from the surface toward the core of the particle. This would be expected in the scenario where the original catalyst particle keeps breaking up internally due to the formation of polyethylene within the core of the particle, which will push the smaller and smaller catalyst fragments toward the external surface. Indeed, a maximum of the $\mathrm{K}_{4}$ volume ratio is now observed closer to the external surface than for the least and moderately fragmented particles. Additionally, the thickness of the $\mathrm{K}_{1,2}$ cluster layers at the external surface has stayed nearly constant throughout the three particles. This means that for this strongest fragmented particle a shift toward a larger contribution of the continuous bisection fragmentation model in the fragmentation behavior is found.

Together with the central slices of all the particles given in Figure 4, we therefore observe that the least fragmented particles mainly consist of a dense catalyst core of the $\mathrm{K}_{4}$ cluster followed by sequential shells of the $K_{3,2,1}$ clusters. Alternatively, the moderately and strongly fragmented particles show the presence of many $\mathrm{K}_{4}$ fragments dispersed throughout the composite particle's volume. The combination of these findings, which is shown schematically in Figure 1f, shows that for particles exhibiting a weak degree of catalyst fragmentation, the shrinking core fragmentation model is dominating; for the moderately fragmented catalyst particles, a more equal contribution of both shrinking core and continuous bisection fragmentation models is observed, and for the strongly fragmentated catalyst particles, the continuous bisection fragmentation model is dominating the overall fragmentation behavior. The formation of polyethylene mainly at the particle's external surface as observed for the weakly fragmented particles can be explained by both internal and external mass transfer limitations or alternatively a higher concentration of active sites at the surface than the core, which can happen when the cocatalyst has not come in contact with the internally located $\mathrm{Ti}^{4+}$ preactive sites upon addition of the $\alpha$-olefin. $^{41}$

The disk analysis plots in Figure 5c report the mean grayscale intensity values per slice along the $X Y$ plane, which represents the mean electron density in a slice. The first particle shows a gradual increase of the mean electron density until a peak is reached close to the central slice along the $X Y$ plane and confirms what was observed with the radial analysis of the $k$-means clusters' volume ratios. That is to say that, also with the disk analysis on the pure grayscale intensity values (so without a $k$-means clustering approach), a gradual change is observed from a low mean electron density phase to that of a high electron density phase. That means that there is a smooth change from a HDPE phase at the surface of the particle toward a catalyst phase at the core of the particle. The $\sim 10$ slices offset of the maximum grayscale intensity value (around slice 50) from the central slice (roughly at slice 40) also confirms why the $K_{3}$ cluster shows a volume ratio of 1 at this first particle's center voxels. Going toward the moderately and strongly fragmented particles, we see that instead of a peak a plateau is reached that maintains a rather constant mean intensity value for more than 50 slices for the moderately fragmented particle and almost 200 slices for the strongly fragmented particle. Furthermore, instead of a smooth gradient from low to high intensity as observed for the weakly fragmented particle a sharp transition is experienced especially for the strongly fragmented particle. This shows that especially for the strongly fragmented particle the catalyst phase is already highly dispersed throughout the formed HDPE phase, where local maxima can be observed even close to the edges with regards to the $X Y$ plane and is additional proof for the continuous bisection fragmentation model playing a significant role in the fragmentation behavior of these two particles.

In the Supporting Information, section 13, a rough estimation is provided on the distribution of how many particles are classified as showing either a weak, moderate, or strong degree of catalyst fragmentation. Based on this rough estimation, respectively, 274, 123, and 37 particles belong to the weak, moderate, and strong classifications of degree of catalyst fragmentation.

\section{CONCLUSIONS}

Using the strength of ptychography X-ray-computed nanotomography to visualize the local mean electron density with an achieved 3-D spatial resolution of $74 \mathrm{~nm}$ over a large, scanned field of view of $120 \times 120 \times 20 \mu \mathrm{m}^{2}$, the heterogeneity in the degree of fragmentation of 434 ethylene-polymerized Ziegler catalyst particles was analyzed and visualized in the early stages of ethylene polymerization under mild reaction conditions and with a high catalyst loading. The highly connected composite particles were successfully segmented in the reconstructed volume using a supervised marker-based watershed algorithm. This segmentation allowed for the analysis of geometrical parameters for each individual particle such as the volume, surface area, equivalent spherical diameter, sphericity, and elongation. The elongation degree of the particle ensemble showed that the composite particles followed the replication phenomena of the slightly elongated pristine Ziegler catalyst particles.

Due to the high degree of mixing between the HDPE and catalyst phases below the achieved 3-D spatial resolution a $k$ means clustering algorithm on the PXCT grayscale intensity values was used to identify a HDPE-rich phase, two highly mixed HDPE-catalyst phases and one catalyst-rich phase. Using these clusters, a fragmentation parameter $V_{\mathrm{r}}$ was designed to study the heterogeneity in the degree of fragmentation and therefore local polymerization activity. This fragmentation parameter is based on the ratio of the summed volumes of the HDPE-rich and highly mixed HDPEcatalyst phases over that of the mean volume of the spatially resolved catalyst fragments. The advantage of this parameter is that it takes into account the following: (i) the catalyst activity in terms of HDPE formation, (ii) the loss of any catalyst fragments that have become too small to spatially resolve them from the HDPE phase, and (iii) the change in the size of the catalyst fragments as a function of polymerization activity. Using this fragmentation parameter, a strong heterogeneity was found within the entire ensemble of 434 composite particles with respect to the degree of catalyst fragmentation. Three representative particles that were categorized with respect to showing either a weak, moderate, or strong degree of catalyst fragmentation at this specific yield of $3.4 \mathrm{~g}$ of HDPE/g catalyst were analyzed in depth. The weakly fragmented composite particle showed mainly a dominating shrinking core 
fragmentation model with hints to the presence of the continuous bisection fragmentation model. For the moderately and strongly fragmented composite particles, the shrinking core fragmentation mode was still observed to occur, but the continuous bisection fragmentation mode had become the dominating pathway for fragmentation, which shows that monomer diffusion toward the interior of the catalyst particle was not limited with respect to the weakly fragmented composite particle; this in turn explains the higher local polymerization activity of these particles. A rough estimation was then performed on how many particles are classified as portraying either a weak, moderate, or strong degree of catalyst fragmentation to give values of, respectively, 274, 123, and 37 particles.

With further improvements with respect to photon flux and beam coherency, such as through the upgrading to fourth generation synchrotron facilities ${ }^{95-97}$ as well as detector acquisition times, the 3-D spatial resolution of PXCT can be pushed below the size of the primary particles of the $\mathrm{MgCl}_{2}$ based framework (as small as $5 \mathrm{~nm}$ ), while maintaining large scanning areas. This will enable a full quantitative approach to study the fragmentation degree of each individual particle with the methodology provided here and can be extended to study other polyolefin catalyst systems, such as the Phillips and metallocene catalysts.

\section{ASSOCIATED CONTENT}

\section{Supporting Information}

The Supporting Information is available free of charge at https://pubs.acs.org/doi/10.1021/jacsau.1c00130.

Sample preparation and characterization, methodology for the reconstruction of the PXCT and X-ray fluorescence data sets, volume expansion and radial distribution calculations (PDF)

Movie S1: Reconstructed PXCT volume rendering of the entire ensemble and of the $k$-means cluster distribution of a single composite particle (MP4) Movie S2: Weakest fragmentation (MP4)

Movie S3: Intermediate fragmentation (MP4)

Movie S4: Strongest fragmentation (MP4)

\section{AUTHOR INFORMATION}

\section{Corresponding Authors}

Bert M. Weckhuysen - Inorganic Chemistry \& Catalysis, Debye Institute for Nanomaterials Science, Utrecht University, 3584 CG Utrecht, The Netherlands; (1) orcid.org/0000-0001-5245-1426;

Email: b.m.weckhuysen@uu.nl

Florian Meirer - Inorganic Chemistry \& Catalysis, Debye Institute for Nanomaterials Science, Utrecht University, 3584

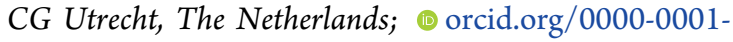
5581-5790; Email: f.meirer@uu.nl

\section{Authors}

Koen W. Bossers - Inorganic Chemistry \& Catalysis, Debye Institute for Nanomaterials Science, Utrecht University, 3584 CG Utrecht, The Netherlands

Roozbeh Valadian - Inorganic Chemistry \& Catalysis, Debye Institute for Nanomaterials Science, Utrecht University, 3584 CG Utrecht, The Netherlands

Jan Garrevoet - Photon Science at Deutsches ElektronenSynchrotron DESY, Hamburg 22603, Germany
Stijn van Malderen - Photon Science at Deutsches ElektronenSynchrotron DESY, Hamburg 22603, Germany

Robert Chan - SABIC, 6160 AH Geleen, The Netherlands

Nic Friederichs - SABIC, 6160 AH Geleen, The Netherlands

John Severn - DSM Materials Science Center, 6167 RD Geleen, The Netherlands

Arnold Wilbers - DSM Materials Science Center, 6167 RD Geleen, The Netherlands

Silvia Zanoni - Inorganic Chemistry \& Catalysis, Debye Institute for Nanomaterials Science, Utrecht University, 3584 CG Utrecht, The Netherlands

Maarten K. Jongkind - Inorganic Chemistry \& Catalysis, Debye Institute for Nanomaterials Science, Utrecht University, 3584 CG Utrecht, The Netherlands

Complete contact information is available at:

https://pubs.acs.org/10.1021/jacsau.1c00130

\section{Author Contributions}

"K.W.B. and R.V. contributed equally to this work.

Notes

The authors declare no competing financial interest.

\section{ACKNOWLEDGMENTS}

We acknowledge DESY (Hamburg, Germany), a member of the Helmholtz Association HGF, for the provision of experimental facilities. Parts of this research were carried out at PETRA III. We would like to thank Jan Willem de Rijk (Utrecht University, UU) for his help on designing and building the low-pressure polymerization setup inside a glovebox and Ad van der Eerden (UU) for fruitful discussions. We would like to thank Dr. An Philippaerts (DSM Materials Science Center) and Dr. Gert de Cremer (DSM Materials Science Center) for providing their insights and knowledge. This research was supported in part through the Maxwell computational resources operated at Deutsches ElektronenSynchrotron (DESY), Hamburg, Germany. This work was funded by The Netherlands Organization for Scientific Research (NWO) in the frame of an NWO-TA grant (No. 731.015.203) with SABIC, DSM Resolve, and the University of Maastricht and an NWO VIDI Grant granted to F.M. (No. 723.015.007).

\section{REFERENCES}

(1) Bett, K. E.; Crossland, B.; Ford, H.; Gardner, A. K. Review of the Engineering Developments in the High Pressure Polyethylene Process 1933-1983. Proceedings of the Golden Jubilee Conference, Polyethylenes 1933-1983; Plastics and Rubber Institute: London, 1983.

(2) Soga, K.; Shiono, T. Ziegler-Natta Catalysts for Olefin Polymerization. Prog. Polym. Sci. 1997, 22, 1503-1546.

(3) Severn, J. R.; Chadwick, J. C.; Duchateau, R.; Friederichs, N. „Bound but Not Gagged”-Immobilizing Single-Site $\alpha$-Olefin Polymerization Catalysts. Chem. Rev. 2005, 105, 4073-4147.

(4) Ziegler, K. Consequences and Development of an Invention. Angew. Chem. 1964, 76, 545-553.

(5) Natta, G. From stereospecific Polymerization to asymmetric autocatalytic Synthesis of Macromolecules. Angew. Chem. 1964, 76, $553-566$.

(6) Kaminsky, W., Ed. Polyolefins: 50 Years after Ziegler and Natta I; Springer: Berlin, 2013.

(7) Böhm, L. L. The Ethylene Polymerization with Ziegler Catalysts: Fifty Years after the Discovery. Angew. Chem., Int. Ed. 2003, 42, 5010-5030. 
(8) Mülhaupt, R. Green polymer chemistry and bio-based plastics: Dreams and reality. Macromol. Chem. Phys. 2013, 214, 159-174.

(9) Hees, T.; Zhong, F.; Stürzel, M.; Mülhaupt, R. Tailoring Hydrocarbon Polymers and All-Hydrocarbon Composites for Circular Economy. Macromol. Rapid Commun. 2019, 40, 1800608.

(10) Vollmer, I.; Jenks, M. J. F.; Roelands, M. C. P.; White, R. J.; Harmelen, T.; Wild, P.; Laan, G. P.; Meirer, F.; Keurentjes, J. T. F.; Weckhuysen, B. M. Beyond Mechanical Recycling: Giving New Life to Plastic Waste. Angew. Chem., Int. Ed. 2020, 59, 15402-15423.

(11) D’Amore, M.; Thushara, K. S.; Piovano, A.; Causà, M.; Bordiga, S.; Groppo, E. Surface Investigation and Morphological Analysis of Structurally Disordered $\mathrm{MgCl}_{2}$ and $\mathrm{MgCl}_{2} / \mathrm{TiCl}_{4}$ Ziegler-Natta Catalysts. ACS Catal. 2016, 6, 5786-5796.

(12) Giunchi, G.; Allegra, J. Structural disorder in microcrystalline $\mathrm{MgCl}_{2}$. J. Appl. Crystallogr. 1984, 17, 172-178.

(13) McKenna, T. F.; Soares, J. B. P. Single particle modelling for olefin polymerization on supported catalysts: A review and proposals for future development. Chem. Eng. Sci. 2001, 56, 3931-3949.

(14) Fernandes, J. A.; Girard, A.-L. Support Designed for Polymerization. In Multimodal Polymers with Supported Catalysts; Albunia, A. R., Prades, F., Jeremic, D., Eds.; Springer Nature: Switzerland, 2019.

(15) Severn, J. R. Recent Developments in Supported Polyolefin Catalysts: A Review. In Multimodal Polymers with Supported Catalysts; Albunia, A. R., Prades, F., Jeremic, D., Eds.; Springer Nature: Switzerland, 2019.

(16) Berger, E., Derroitte, J.-L. Polymerization of Olefins. U.S. Patent Appl. US3,901,863, 1975.

(17) Bart, J. C. J.; Roovers, W. Magnesium chloride - ethanol adducts. J. Mater. Sci. 1995, 30, 2809-2820.

(18) Gelus, E. Process for Polymerizing Olefin with a Ziegler-Natta Catalyst. European Patent Appl. EP0,703,246, 2002.

(19) Gnanakumar, E. S.; Gowda, R. R.; Kunjir, S.; Ajithkumar, T. G.; Rajamohanan, P. R.; Chakraborty, D.; Gopinath, C. S. $\mathrm{MgCl}_{2} \bullet 6 \mathrm{CH}_{3} \mathrm{OH}$ : A Simple Molecular Adduct and Its Influence as a Porous Support for Olefin Polymerization. ACS Catal. 2013, 3, 303-311.

(20) Matsuura, M.; Fujita, T. Catalyst Component for Polymerization of Olefins. U.S. Patent Appl. US4,703,026, 1987.

(21) Pullukat, T. J.; Hoff, R. E. Silica-based Ziegler-Natta catalysts: A patent review. Catal. Rev.: Sci. Eng. 1999, 41, 389-428.

(22) McKenna, T. F. L.; Di Martino, A.; Weickert, G.; Soares, J. B. P. Particle Growth During the Polymerisation of Olefins on Supported Catalysts, 1 - Nascent Polymer Structures. Macromol. React. Eng. 2010, 4, 40-64.

(23) Simonazzi, T.; Cecchin, G.; Mazzullo, S. An outlook on progress in polypropylene-based polymer technology. Prog. Polym. Sci. 1991, 16, 303-329.

(24) Ferrero, M. A.; Chiovetta, M. G. Catalyst fragmentation during propylene polymerization: Part I. The effects of grain size and structure. Polym. Eng. Sci. 1987, 27, 1436-1447.

(25) Ferrero, M. A.; Chiovetta, M. G. Catalyst fragmentation during propylene polymerization: Part II. Microparticle diffusion and reaction effects. Polym. Eng. Sci. 1987, 27, 1448-1460.

(26) Ferrero, M. A.; Chiovetta, M. G. Catalyst fragmentation during propylene polymerization: Part III. Bulk polymerization process simulation. Polym. Eng. Sci. 1991, 31, 886-903.

(27) Estenoz, D. A.; Chiovetta, M. G. A structural model for the catalytic polymerization of ethylene using chromium catalysts. Part I: description and solution. Polym. Eng. Sci. 1996, 36, 2208-2240.

(28) Horácková, B.; Grof, Z.; Kosek, J. Dynamics of fragmentation of catalyst carries in catalytic polymerization of olefins. Chem. Eng. Sci. 2007, 62, 5264-5270.

(29) Huo, C.; Ren, X. H.; Liu, B. P.; Yang, Y. R.; Rong, S. X. Fractal Approach for Modeling the Morphology Evolution of Olefin Polymerization with Heterogeneous Catalysts. J. Appl. Polym. Sci. 2003, 90, 1463-1470.
(30) Hammawa, H.; Wanke, S. E. Gas phase olefin polymerization over supported metallocene/MAO catalysts: influence of support on activity and polydispersity. Polym. Int. 2006, 55, 426-434.

(31) Hammawa, H.; Wanke, S. E. Influence of Support Friability and Concentration of $\alpha$-Olefins on Gas-Phase Ethylene Polymerization over Polymer-Supported Metallocene/Methylaluminoxane Catalysts. J. Appl. Polym. Sci. 2007, 104, 514-527.

(32) Abboud, M.; Denifl, P.; Reichert, K. H. Fragmentation of Ziegler-Natta catalyst particles during propylene polymerization. Macromol. Mater. Eng. 2005, 290, 558-564.

(33) Seda, L.; Zubov, A.; Bobak, M.; Kosek, J.; Kantzas, A. Transport and Reaction Characteristics of Reconstructed Polyolefin Particles. Macromol. React. Eng. 2008, 2, 495-512.

(34) Nooijen, G. A. H. Ziegler/Natta catalysts in particle form ethylene polymerization: The effect of polymerization start-up on catalyst activity and morphology of the produced polymer. Catal. Today 1991, 11, 35-46.

(35) Hassan Nejad, M.; Ferrari, P.; Pennini, G.; Cecchin, G. Ethylene Homo- and Copolymerization over $\mathrm{MgCl}_{2}-\mathrm{TiCl}_{4}$ Catalysts: Polymerization Kinetics and Polymer Particle Morphology. J. Appl. Polym. Sci. 2008, 108, 3388-3402.

(36) Knoke, S.; Ferrari, D.; Tesche, B.; Fink, G. Microkinetic Videomicroscopic Analysis of Olefin Polymerization with a Supported Metallocene Catalyst. Angew. Chem., Int. Ed. 2003, 42, 5090-5093.

(37) Pater, J. T. M.; Weickert, G.; van Swaaij, W. P. M. Polymerization of Liquid Propylene with a Fourth-Generation Ziegler-Natta Catalyst: Influence of Temperature, Hydrogen, Monomer Concentration, and Prepolymerization Method on Powder Morphology. J. Appl. Polym. Sci. 2003, 87, 1421-1435.

(38) Pater, J. T. M.; Weickert, G.; Loos, J.; van Swaaij, W. P. M. High precision prepolymerization of propylene at extremely low reaction rates-kinetics and morphology. Chem. Eng. Sci. 2001, 56, $4107-4120$

(39) Qi, M.; Zhang, B.; Fu, Z.; Xu, J.; Fan, Z. Millimeter-size polyethylene hollow spheres synthesized with $\mathrm{MgCl}_{2}$-supported Ziegler-Natta catalyst. J. Appl. Polym. Sci. 2016, 133, 43207-43217.

(40) Laurence, R. L.; Chiovetta, M. G. In Polymer Reaction Engineering; Reicher, K. H., Geisler, G., Eds.; Hasuer-Verlag: München, 1983; pp 74-112.

(41) Nooijen, G. A. H. On the importance of diffusion of cocatalyst molecules through heterogeneous Ziegler/natta catalysts. Eur. Polym. J. 1994, 30, 11-15.

(42) Weickert, G.; Meier, G. B.; Pater, J. T. M.; Westerterp, K. R. The particle as microreactor: Catalytic propylene polymerizations with supported metallocenes and Ziegler-Natta catalysts. Chem. Eng. Sci. 1999, 54, 3291-3296.

(43) Fink, G.; Steinmetz, B.; Zechlin, J.; Przybyla, C.; Tesche, B. Propylene Polymerization with Silica-Supported Metallocene/MAO Catalysts. Chem. Rev. 2000, 100, 1377-1390.

(44) Rönkkö, H.-L.; Korpela, T.; Knuuttila, H.; Pakkanen, T. T.; Denifl, P.; Leinonen, T.; Kemell, M.; Leskelä, M. Particle growth and fragmentation of solid self-supported Ziegler-Natta-type catalysts in propylene polymerization. J. Mol. Catal. A: Chem. 2009, 309, 40-49.

(45) Kakugo, M.; Sadatoshi, H.; Yokoyama, M.; Kojima, M. Transmission electron microscopic observation of nascent polypropylene particles using a new staining method. Macromolecules 1989, 22, 547-551.

(46) Kakugo, M.; Sadatoshi, H.; Sakai, J.; Yokoyama, M. Growth of polypropylene particles in heterogeneous Ziegler-Natta polymerization. Macromolecules 1989, 22, 3172.

(47) Noristi, L.; Marchetti, E.; Baruzzi, G.; Sgarzi, P. Investigation on the Particle Growth Mechanism in Propylene Polymerization with $\mathrm{MgCl}_{2}$-Supported Ziegler-Natta Catalysts. J. Polym. Sci., Part A: Polym. Chem. 1994, 32, 3047-3059.

(48) Egorov, V. M.; Ivan'kova, E. M.; Kulik, V. B.; Lebedev, D. V.; Myasnikova, L. P.; Marikhin, V. A.; Radovanova, E. I.; Yagovkina, M. A.; Seydewitz, V.; Goerlitz, S.; Michler, G. H.; Nöchel, U.; BaltaCalleja, F. J. Features of the Amorphous-Crystalline Structure of UHMWPE. Polym. Sci., Ser. C 2011, 53, 75-88. 
(49) Zheng, X.; Smit, M.; Chadwick, J. C.; Loos, J. Fragmentation Behavior of Silica-Supported Metallocene/MAO Catalyst in the Early Stages of Olefin Polymeriation. Macromolecules 2005, 38, 4673-4678.

(50) Zheng, X.; Loos, J. Morphology Evolution in the Early Stages of Olefin Polymerization. Macromol. Symp. 2006, 236, 249-258.

(51) Zheng, X.; Pimplapure, M. S.; Weickert, G.; Loos, J. Influence of Copolymerization on Fragmentation Behavior Using Ziegler-Natta Catalysts. Macromol. Rapid Commun. 2006, 27, 15-20.

(52) Silva, F. M.; Broyer, K. P.; Novat, C.; Lima, E. L.; Pinto, J. C.; McKenna, T. F. Investigation of Catalyst Fragmentation in Gas-Phase Olefin Polymerisation: A Novel Short Stop Reactor. Macromol. Rapid Commun. 2005, 26, 1846-1853.

(53) Di Martino, A.; Broyer, J.; Spitz, R.; Weickert, G.; McKenna, T. F. A Rapid Quenched-Flow Device for the Characterisation of the Nascent Polymerisation of Ethylene under Industrial Conditions. Macromol. Rapid Commun. 2005, 26, 215-220.

(54) Machado, F.; Lima, E. L.; Pinto, J. C.; McKenna, T. F. Evolution of the Initial Stages of Gas-Phase Ethylene Polymerizations with a $\mathrm{SiO}_{2}$-Supported Ziegler-Natta Catalyst. Macromol. React. Eng. 2009, 3, 47-57.

(55) McKenna, T. F. L.; Tioni, E.; Ranieri, M. M.; Alizadeh, A.; Boisson, C.; Monteil, V. Catalytic olefin polymerization at short times: Studies using specially adapted reactors. Can. J. Chem. Eng. 2013, 91, 669-686.

(56) Jacobsen, C. X-ray Tomography in X-ray Microscopy; Cambridge University Press: Cambridge, 2020; pp 321-349.

(57) Beale, A. M.; Jacques, S. D. M.; Weckhuysen, B. M. Chemical imaging of catalytic solid with synchrotron radiation. Chem. Soc. Rev. 2010, 39, 4656-4672.

(58) Gonzalez-Jimenez, I. D.; Cats, K.; Davidian, T.; Ruitenbeek, M.; Meirer, F.; Liu, Y.; Nelson, J.; Andrews, J. C.; Pianetta, P.; de Groot, F. M. F.; Weckhuysen, B. M. Hard X-ray Nanotomography of Catalytic Solids at Work. Angew. Chem., Int. Ed. 2012, 51, 1198611990.

(59) Cats, K. H.; Gonzalez-Jimenez, I. D.; Liu, Y.; Nelson, J.; Van Campen, D.; Meirer, F.; van der Eerden, A. M. J.; De Groot, F. M. F.; Andrews, J. C.; Weckhuysen, B. M. X-ray nanoscopy of cobalt Fischer-Tropsch catalysts at work. Chem. Commun. 2013, 49, 46224624.

(60) Beale, A. M.; Jacques, S. D. M.; Gibson, E. K.; Di Michiel, M. Progress towards five-dimensional diffraction imaging of functional materials under process conditions. Coord. Chem. Rev. 2014, 277, 208-223.

(61) Price, S. W. T.; Ignatyev, K.; Geraki, K.; Basham, M.; Filik, J.; Vo, N. T.; Witte, P. T.; Beale, A. M.; Mosselmans, J. F. W. Chemical imaging of single catalyst particles with scanning $\mu$-XANES-CT and $\mu$ XRF-CT. Phys. Chem. Chem. Phys. 2015, 17, 521-529.

(62) Cats, K. H.; Andrews, J. C.; Stéphan, O.; March, K.; Karunakaran, C.; Meirer, F.; de Groot, F. M. F.; Weckhuysen, B. M. Active phase distribution changes within a catalyst particle during Fischer-Tropsch synthesis as revealed by multi-scale microscopy. Catal. Sci. Technol. 2016, 6, 4438-4449.

(63) Price, S. W. T.; Martin, D. J.; Parsons, A. D.; Sławiński, W. A.; Vamvakeros, A.; Keylock, S. J.; Beale, A. M.; Mosselmans, J. F. W. Chemical Imaging of Fischer-Tropsch catalysts under operating conditions. Sci. Adv. 2017, 3, e1602838.

(64) Meirer, F.; Weckhuysen, B. M. Spatial and temporal exploration of heterogeneous catalysts with synchrotron radiation. Nat. Rev. Mater. 2018, 3, 324-340.

(65) Vamvakeros, A.; Jacques, S. D. M.; Di Michiel, M.; Matras, D.; Middelkoop, V.; Ismagilov, I. Z.; Matus, E. V.; Kuznetsov, V. V.; Drnec, J.; Senecal, P.; Beale, A. M. 5D operando tomographic diffraction imaging of a catalyst bed. Nat. Commun. 2018, 9, 4751.

(66) Vamvakeros, A.; Matras, D.; Jacques, S. D. M.; di Michiel, M.; Price, S. W. T.; Senecal, P.; Aran, M. A.; Middelkoop, V.; Stenning, G. B. G.; Mosselmans, J. F. W.; Ismagilov, I. Z.; Beale, A. M. Real-time multi-length scale chemical tomography of fixed bed reactors during the oxidative coupling of methane reaction. J. Catal. 2020, 386, 3952 .
(67) Sheppard, T. L.; Price, S. W. T.; Benzi, F.; Baier, S.; Klumpp, M.; Dittmeyer, R.; Schwieger, W.; Grunwaldt, J.-D. In Situ Multimodal 3D Chemical Imaging of a Hierarchically Structured Core@Shell Catalyst. J. Am. Chem. Soc. 2017, 139, 7855-7863.

(68) Fam, Y.; Sheppard, T. L.; Diaz, A.; Scherer, T.; Holler, M.; Wang, W.; Wang, D.; Brenner, P.; Wittstock, A.; Grunwaldt, J.-D. Correlative Multiscale 3D Imaging of a Hierarchical Nanoporous Gold Catalyst by Electron, Ion and X-ray Nanotomography. ChemCatChem 2018, 10, 2858-2867.

(69) Becher, J.; Ferreira Sanchez, D.; Doronkin, D. E.; Zengel, D.; Motta Meira, D.; Pascarelli, S.; Grunwaldt, J.-D.; Sheppard, T. L. Chemical gradients in automotive Cu-SSZ-13 catalysts for NOx removal revealed by operando X-ray spectrotomography. Nat. Catal. 2021, 4, 46-53.

(70) Fam, Y.; Sheppard, T. L.; Becher, J.; Scherhaufer, D.; Lambach, H.; Kulkarni, S.; Keller, T. F.; Wittstock, A.; Wittwer, F.; Seyrich, M.; Brueckner, D.; Kahnt, M.; Yang, X.; Schropp, A.; Stierle, A.; Schroer, C. G.; Grunwaldt, J.-D. A versatile nanoreactor for complementary in situ X-ray and electron microscopy studies in catalysis and materials science. J. Synchrotron Radiat. 2019, 26, 1769-1781.

(71) da Silva, J. C.; Mader, K.; Holler, M.; Haberthur, D.; Diaz, A.; Guizar-Sicairos, M.; Cheng, W.-C.; Shu, Y.; Raabe, J.; Menzel, A.; van Bokhoven, J. A. Assessment of the 3 D Pore Structure and Individual Components of the Preshaped Catalyst Bodies by X-ray Imaging. ChemCatChem 2015, 7, 413-416.

(72) Ihli, J.; Ferreira Sanchez, D.; Jacob, R. R.; Cuartero, V.; Mathon, O.; Krumeich, F.; Borca, C.; Huthwelker, T.; Cheng, W.-C.; Shu, Y.; Pascarelli, S.; Grolimund, D.; Menzel, A.; van Bokhoven, J. A. Localization and Speciation of Iron Impurities within a Fluid Catalytic Cracking Catalyst. Angew. Chem., Int. Ed. 2017, 56, 14031-14035.

(73) Ihli, J.; Jacob, R. R.; Holler, M.; Guizar-Sicairos, M.; Diaz, A.; Da Silva, J. C.; Ferreira Sanchez, D.; Krumeich, F.; Grolimund, D.; Taddei, M.; Cheng, W.-C.; Shu, Y.; Menzel, A.; Van Bokhoven, J. A. A three-dimensional view of structural changes caused by deactivation of fluid catalytic cracking catalysts. Nat. Commun. 2017, 8, 809.

(74) Ihli, J.; Diaz, A.; Shu, Y.; Guizar-Sicairos, M.; Holler, M.; Wakonig, K.; Odstrcil, M.; Li, T.; Krumeich, F.; Müller, E.; Cheng, W.-C.; van Bokhoven, J. A.; Menzel, A. Resonant Ptychographic Tomography Facilitates Three-Dimensional Quantitative Colocalization of Catalyst Components and Chemical Elements. J. Phys. Chem. C 2018, 122, 22920-22929.

(75) Bare, S. R.; Charochak, M. E.; Kelly, S. D.; Lai, B.; Wang, J.; Chen-Wiegart, Y. K. Characterization of a Fluidized Catalytic Cracking Catalyst on Ensemble and Individual Particle Level by Xray Micro- and Nanotomography, Micro-X-ray Fluorescence, and micro-X-ray Diffraction. ChemCatChem 2014, 6, 1482.

(76) Meirer, F.; Morris, D. T.; Kalirai, S.; Liu, Y.; Andrews, J. C.; Weckhuysen, B. M. Mapping Metals Incorporation of a Whole Single Catalyst Particle Using Element Specific X-ray Nanotomography. J. Am. Chem. Soc. 2015, 137, 102-105.

(77) Meirer, F.; Kalirai, S.; Morris, D.; Soparawalla, S.; Liu, Y.; Mesu, G.; Andrews, J. C.; Weckhuysen, B. M. Life and death of a single catalytic cracking particle. Sci. Adv. 2015, 1, e1400199.

(78) Meirer, F.; Kalirai, S.; Weker, J. N.; Liu, Y.; Andrews, J. C.; Weckhuysen, B. M. Agglutination of single catalyst particles during fluid catalytic cracking as observed by X-ray nanotomography. Chem. Commun. 2015, 51, 8097-8100.

(79) Kalirai, S.; Boesenberg, U.; Falkenberg, G.; Meirer, F.; Weckhuysen, B. M. X-ray Fluorescence Tomography of Aged FluidCatalytic-Cracking Catalyst Particles Reveals Insight into Metal Deposition Processes. Chem CatChem 2015, 7, 3674-3682.

(80) Kalirai, S.; Paalanen, P. P.; Wang, J.; Meirer, F.; Weckhuysen, B. M. Visualizing Dealumination of a Single Zeolite Domain in a RealLife Catalytic Cracking Particle. Angew. Chem., Int. Ed. 2016, 55, 11134-11138.

(81) Wise, A. M.; Weker, J. N.; Kalirai, S.; Farmand, M.; Shapiro, D. A.; Meirer, F.; Weckhuysen, B. M. Nanoscale Chemical Imaging of an Individual Catalyst Particle with Soft X-ray Ptychography. ACS Catal. 2016, 6, 2178-2181. 
(82) Gambino, M.; Veselý, M.; Filez, M.; Oord, R.; Ferreira Sanchez, D.; Grolimund, D.; Nesterenko, N.; Minoux, D.; Maquet, M.; Meirer, F.; Weckhuysen, B. M. Nickel Poisoning of a Cracking Catalyst Unravelled by Single-Particle X-ray Fluorescence-Diffraction-Absorption Tomography. Angew. Chem., Int. Ed. 2020, 59, 3922-3927.

(83) Vesely, M.; Valadian, R.; Merten Lohse, L.; Toepperwien, M.; Spiers, K.; Garrevoet, J.; Vogt, E. T. C.; Salditt, T.; Weckhuysen, B. M.; Meirer, F. 3-D X-ray Nanotomography Reveals Different Carbon Deposition Mechanisms in a Single Catalyst Particle. ChemCatChem 2021, DOI: $10.1002 /$ cctc. 202100276.

(84) Conner, W. C.; Webb, S. W.; Spanne, P.; Jones, K. W. Use of $\mathrm{X}$-ray microscopy and synchrotron microtomography to characterize polyethylene polymerization particles. Macromolecules 1990, 23, $4742-4747$.

(85) Ferrero, M. A.; Sommer, R.; Spanne, P.; Jones, K. W.; Conner, W. C. X-ray microtomography studies of nascent polyolefin particles polymerized over magnesium chloride-supported catalysts. J. Polym. Sci., Part A: Polym. Chem. 1993, 31, 2507-2512.

(86) Jones, K. W.; Spanne, P.; Lindquist, W. B.; Conner, W. C.; Ferrero, M. Determination of polymerization particle morphology using synchrotron computed microtomography. Nucl. Instrum. Methods Phys. Res., Sect. B 1992, 68, 105-110.

(87) Boden, S.; Bieberle, M.; Weickert, G.; Hampel, U. Threedimensional analysis of macroporosity distributions in polyolefin particles using X-ray microtomography. Powder Technol. 2008, 188, $81-88$.

(88) Meisterová, L.; Zubov, A.; Smolná, K.; Štěpánek, F.; Kosek. Xray Tomography Imaging of Porous Polyolefin Particles in an Electron Microscope. Macromol. React. Eng. 2013, 7, 277-280.

(89) Bossers, K. W.; Valadian, R.; Zanoni, S.; Smeets, R.; Friederichs, N.; Garrevoet, J.; Meirer, F.; Weckhuysen, B. M. Correlated X-ray Ptychography and Fluorescence Nano-Tomography on the Fragmentation Behavior of an Individual Catalyst Particle during the Early Stages of Olefin Polymerization. J. Am. Chem. Soc. 2020, 142, 3691-3695.

(90) Beucher, S.; Meyer, F. The Morphological Approach to Segmentation: The Watershed Transformation. In Mathematical Morphology in Image Processing; Dougherty, E., Ed.; Taylor \& Francis Inc., 1993.

(91) Nielsen, M. S.; Munk, M. B.; Diaz, A.; Pedersen, E. B. L.; Holler, M.; Bruns, S.; Risbo, J.; Mortensen, K.; Feidenhans'l, R. Ptychographic X-ray computed tomography of extended colloidal networks in food emulsions. Food Struct. 2016, 7, 21-28.

(92) Simonazzi, T.; Cecchin, G.; Mazzullo, S. An outlook on progress in polypropylene-based polymer technology. Prog. Polym. Sci. 1991, 16, 303-329.

(93) Cheruvathur, A. V.; Langner, E. H. G.; Niemantsverdriet, J. W.; Thüne, P. C. In Situ ATR-FTIR Studies on $\mathrm{MgCl}_{2}$-Diisobutyl Phthalate Interactions in Thin Film Ziegler-Natta Catalysts. Langmuir 2012, 28, 2643-2651.

(94) Liu, D.; Yu, J. Otsu Method and K-means. Proceedings of the Ninth International Conference on Hybrid Intelligent Systems 2009, 344-349.

(95) Schroer, C. G.; Agapov, I.; Brefeld, W.; Brinkmann, R.; Chae, Y.-C.; Chao, H.-C.; Eriksson, M.; Keil, J.; Nuel Gavalda, X.; Rohlsberger, R.; Seeck, O. H.; Sprung, M.; Tischer, M.; Wanzenberg, R.; Weckert, E. PETRA IV: the ultralow-emittance source project at DESY. J. Synchrotron Radiat. 2018, 25, 1277-1290.

(96) Johansson, U.; Vogt, U.; Mikkelsen, A. NanoMAX: A hard x-ray nanoprobe beamline at MAX IV. Proc. SPIE 2013, 88510L.

(97) Raimondi, P. ESRF-EBS: The Extremely Brilliant Source Project. Synchrotron Radiat. News 2016, 29, 8-15. 